\title{
Review of Current Surgical Treatments for Lymphedema
}

\author{
Jay W. Granzow, MD, MPH, FACS ${ }^{1,2}$, Julie M. Soderberg, MPT, ATC, CSCS, CLT-LANA ${ }^{3}$, Amy H. Kaji, MD, \\ PhD, MPH ${ }^{1}$, and Christine Dauphine, MD, FACS ${ }^{1}$
}

${ }^{1}$ UCLA Division of Plastic Surgery, Harbor-UCLA Medical Center, Torrance, CA; ${ }^{2}$ UCLA David Geffen School of Medicine, Los Angeles, CA; ${ }^{3}$ Providence Little Company of Mary Hospital, Torrance, CA

\begin{abstract}
Background. The current mainstay of lymphedema therapy has been conservative nonsurgical treatment. However, surgical options for lymphedema have been reported for over a century. Early surgical procedures were often invasive and disfiguring, and they often had only limited long-term success. In contrast, contemporary surgical techniques are much less invasive and have been shown to be effective in reducing excess limb volume, the risk of cellulitis, and the need for compression garment use and lymphedema therapy. Microsurgical procedures such as lymphaticovenous anastomosis and vascularized lymph node transfer lymphaticolymphatic bypass can treat the excess fluid component of lymphedema swelling that presents as pitting edema. Suction-assisted protein lipectomy is a minimally invasive procedure that addresses the solid component of lymphedema swelling that typically occurs later in the disease process and presents as chronic nonpitting lymphedema. These surgical techniques are becoming increasingly popular and their success continues to be documented in the medical literature. We review the efficacy and limitations of these contemporary surgical procedures for lymphedema.
\end{abstract}

Methods. A Medline literature review was performed of lymphedema surgery, vascularized lymph node transfer, lymphaticovenous anastomosis, lymphatic liposuction, and lymphaticolymphatic bypass with particular emphasis on developments within the past 10 years. A literature review of technique, indications, and outcomes of the surgical treatments for lymphedema was undertaken.

\section{(C) Society of Surgical Oncology 2014}

First Received: 28 October 2013;

Published Online: 21 February 2014

J. W. Granzow, MD, MPH, FACS

e-mail: DrJay@PlasticSurgery.LA
Results. Surgical treatments have evolved to become less invasive and more effective.

Conclusions. With proper diagnosis and the appropriate selection of procedure, surgical techniques can be used to treat lymphedema safely and effectively in many patients when combined with integrated lymphedema therapy.

Lymphedema is a progressive and debilitating condition associated with dysfunction of the lymphatic system. While a small percentage of cases are congenital, most patients in developed countries present with lymphedema resulting from treatment of malignancy. The true incidence of lymphedema is difficult to determine as a result of significant differences in diagnostic criteria. However, lymphedema is reported to occur in up to $49 \%$ of breast, $20 \%$ of gynecologic, $16 \%$ of melanoma, $10 \%$ of genitourinary, and $6 \%$ head and neck cancer patients after lymph node dissection and/or radiotherapy. Even among patients who undergo isolated axillary sentinel lymph node biopsy, up to $7 \%$ have measurable arm differences, and up to $10 \%$ have subjective symptoms of lymphedema. ${ }^{1-8}$

Acquired lymphedema results from the accumulation of lymphatic fluid in the affected limb after interruption of normal lymphatic drainage channels. Initially, swelling is due to excess lymphatic fluid and is characterized by pitting edema. This is the fluid phase of the disease. If untreated or undertreated, the chronic accumulation of inflammatory lymphatic fluids is thought to incite fibrocyte and adipocyte activation and eventually lead to gradual deposition of fat and fibrotic solids. ${ }^{9,10}$ This solid phase is characterized by nonpitting edema, with solids representing over $90 \%$ of the excess volume in many chronic lymphedema patients. ${ }^{11-13}$ The time frame for this transition from fluid to solid can vary considerably between patients.

Traditional treatment for lymphedema has been an initial course of complete decongestive therapy (CDT) administered by a certified lymphedema therapist followed 


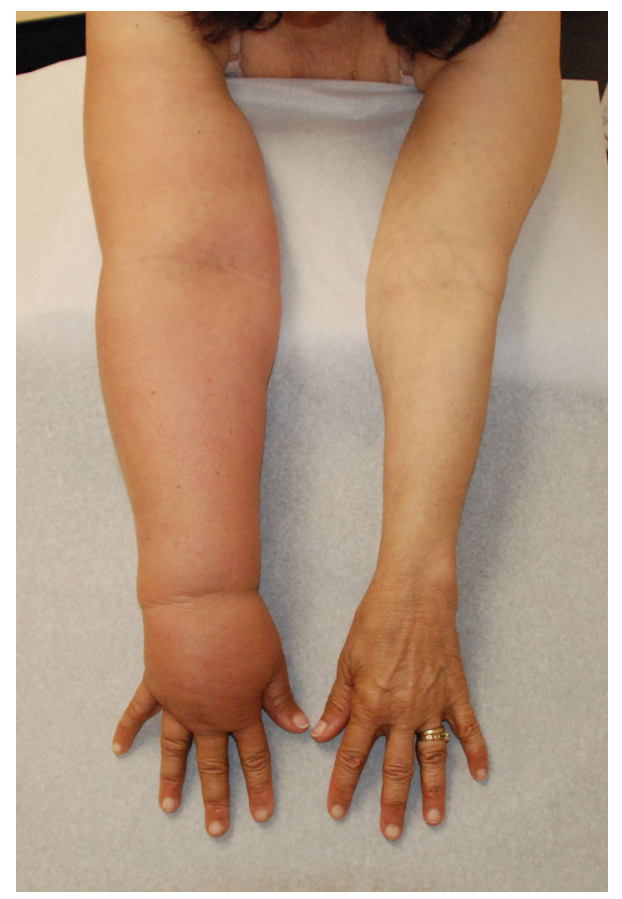

FIG. 1 Cellulitis in right arm of patient with lymphedema

by maintenance treatments by the therapist or patient. CDT consists of multiple components: manual lymph drainage/ massage, compression bandaging, therapeutic exercise, and careful skin care. ${ }^{14-16}$ CDT can provide improvements in many patients when therapy is initiated early in the course of disease. However, the maintenance therapy and the ongoing use of compression garments required afterward must be continued indefinitely in order to remain effective. Adjunct treatment modalities such as the use of low-level topical lasers and/or mechanical compression pumps also have been used. ${ }^{17,18}$ High treatment costs, variability in the quality of therapy and compression garments, lack of adequate insurance coverage, and delayed diagnosis often hinder prompt access to sufficient treatment. ${ }^{19,20}$ Patients may develop chronic pain, anxiety, or depression as well as difficulties with range of motion, gait, activities of daily living, stress on their joints, and fitting into normal clothing. ${ }^{21,22}$ Furthermore, lymphedema swelling more than doubles the risks of developing cellulitis in the affected extremity. Such cellulitis typically progresses rapidly and is much more severe in patients with lymphedema than patients without lymphedema, and management often requires hospitalization for intravenous antibiotics, with some patients requiring long-term, continual low-dose antibiotic prophylaxis (Fig. 1). In rare cases, chronic lymphedema is associated with increased incidence of malignancies such as lymphangiosarcoma (Stewart-Treves syndrome), Kaposi sarcoma, and lymphoma. ${ }^{23,24}$

Surgical procedures to treat lymphedema have existed for over a century. The Charles procedure was first reported in
1912. ${ }^{25}$ This operation involved an aggressive resection of skin and soft tissue down to the deep fascia, followed by skin grafting over the excised area. The Charles procedure achieved debulking of the limb but was not as effective at managing ongoing lymphatic stasis. The first attempts at preservation of lymphatic function were described by Sistrunk and later Thompson. ${ }^{26-28}$ However, the results of these early procedures often were ineffective and disfiguring. These procedures have largely been abandoned except in extreme cases of lymphedema elephantiasis, where massive skin thickening and swelling may necessitate direct tissue excision.

In contrast, contemporary surgical approaches to manage lymphedema are now much less invasive and involve microsurgical approaches to reduce excess lymphatic fluid or minimally invasive approaches to remove accumulated protein solids within the affected limb.

\section{VASCULARIZED LYMPH NODE TRANSFER (VLNT)}

VLNT was first described over 20 years ago. ${ }^{29}$ The procedure involves the microsurgical transfer of a lymphaticcontaining soft tissue flap along with its arteriovenous supply from a donor site such as the lateral groin, chest wall, or neck to the affected limb, groin, or axilla (Fig. 2). Obstructing scar tissue is released, and the vascular circulation is reestablished in the transferred flap. The lymphatics and small peripheral flap vessels are then allowed to heal primarily with the lymphatics and small vessels present at the recipient site. Varying donor and recipient sites are used, but most microsurgeons opt to move lymph nodes from the lateral groin to the affected axilla, while others choose to transfer tissue to the wrist or ankle. ${ }^{30-36}$

If simultaneous breast reconstruction is performed, the lymph node flap can be transferred together with a deep inferior epigastric perforator (DIEP) abdominal soft tissue flap. In such cases, a DIEP flap is used instead of a transverse rectus abdominis myocutaneous (TRAM) flap, both to decrease postoperative abdominal morbidity and to allow better geometry of inset for the lymph node flap in the axilla.

In some patients, improvements of lymphedema swelling can be observed immediately in the hospital after VLNT at a time before healing between donor and native lymphatics could have taken place. While the mechanism of improvement is unclear, the release of scar tissue in the previously operated and/or irradiated lymphatic bed has been postulated to account for this observation. Indeed, studies have shown some improvement in lymphedema after breast reconstruction with autologous flaps alone. ${ }^{37}$ Later in the postoperative period, healing of transplanted lymphatics to native lymphatics at the recipient site and removal of lymphatic fluid by a direct pumping mechanism may provide further fluid drainage. Direct healing of transplanted lymphatics has been 

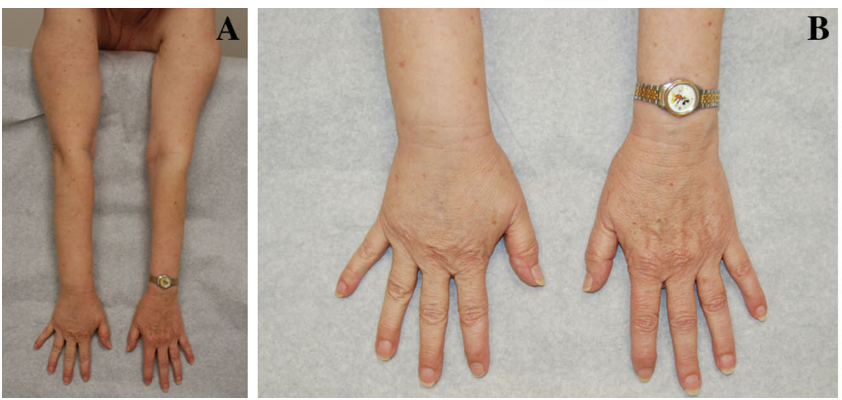

FIG. 2 VLNT imaging. Patient with right arm lymphedema after treatment of right breast cancer treated with right lumpectomy and axillary lymph node dissection. Lymphedema swelling was progressing despite conservative therapy and compression garment use. Patient was then treated with bilateral mastectomy and reconstructed
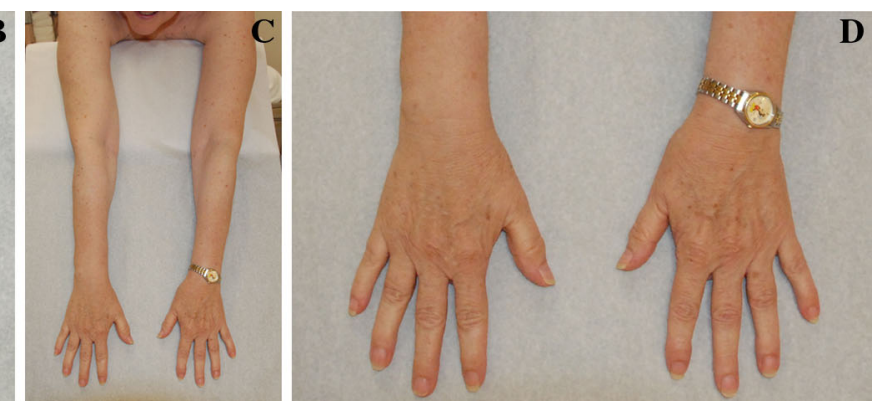

with bilateral DIEP flaps and right VLNT. After surgery, she has minimal volume excess and does not require compression garment use or lymphedema therapy. a, b Before surgery. c, d At 29 months after surgery
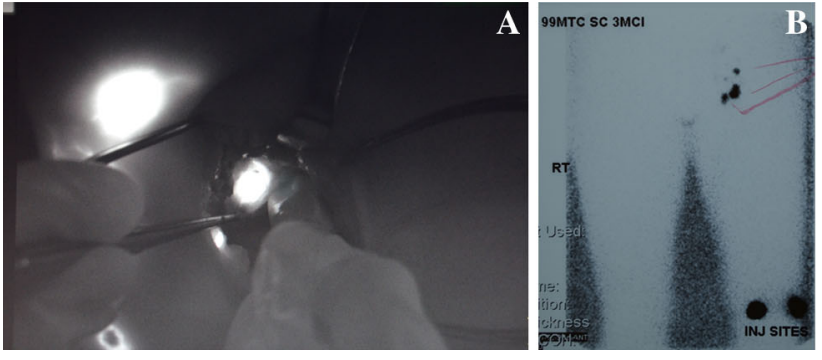

FIG. 3 VLNT imaging. a Intraoperative localization of left torso lymph nodes. Indocyanine green injected intradermally is taken up by torso lymph nodes and illuminates on laser imaging. b, c Preoperative

shown to occur in animal models and in vivo in transplanted free flaps and likely accounts for some of the improvements observed and the success found by those using recipient sites such as the wrist or ankle. ${ }^{34,38,39}$

The main disadvantage of the VLNT procedure is the potential but unlikely risk for donor site morbidity. Careful selection and collection of lymphatics during the procedure is used to minimize risk of disturbing lymphatics at the donor site. In a groin donor site, only the most lateral lymphatics are collected to leave the lymphatics that primarily drain the leg intact. Most authors report no adverse outcomes at the donor sites for VLNT. However, one study reported a small change in the postoperative lymphoscintigraphies in donor site legs, and another study described new-onset lymphedema in donor limbs. ${ }^{40,41}$ Intraoperative laser imaging of lymph nodes with indocyanine green dye can guide selective VLNT lymph node collection. Sentinel lymph node mapping of donor sites with technetium tracer and the collection of lymph nodes other than the sentinel nodes can further improve safety (Fig. 3). ${ }^{11}$

\section{LYMPHATICOVENOUS ANASTOMOSIS (LVA)}

LVA was first described in the 1970s. The procedure involves the connection of multiple lymphatic vessels with
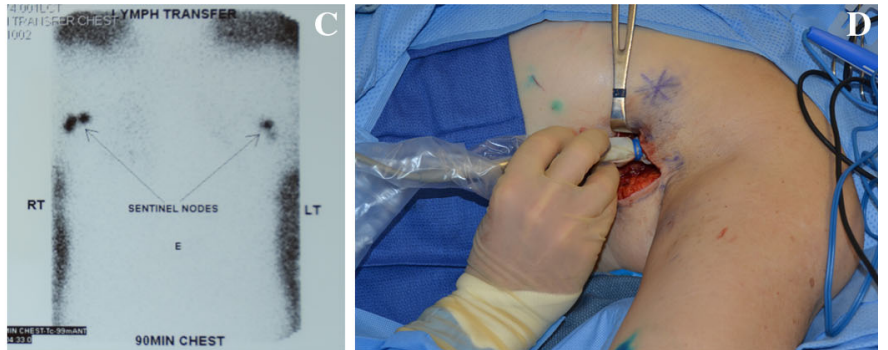

sentinel lymph node mapping of groin and axilla in 2 patients for VLNT collection. d Intraoperative Tc-99 sentinel lymph node localization is performed to avoid damage to sentinel lymph nodes

small adjacent venules to decrease swelling. This allows excess lymph to bypass areas of low or obstructed lymph flow and drain directly into the venous system. Supermicrosurgical techniques are required as most lymphatics range from 0.1 to $0.6 \mathrm{~mm}$ in diameter. ${ }^{42-48}$ Intraoperative identification of lymphatic vessels is facilitated both with Lymphazurin dye and also with laser angiography using indocyanine green (Fig. 4).

The surgical risks of LVA are low. The lymphatics that are connected are relatively superficial, and only a fraction of the lymphatics present in an affected arm or leg are used for anastomosis.

\section{LYMPHATICOLYMPHATIC BYPASS}

First described in 1986 by Baumeister et al., ${ }^{49}$ this procedure involves the transfer of healthy, functioning lymphatic vessels from a donor area, usually the inner thigh, and sewing the lymphatic vessels of the donor site directly to the lymphatic vessels of the affected limb. Although the authors reported improvements in both limb volumes and the lymphatic transport index, volume reductions were easier to achieve in arms than legs. Moreover, this type of procedure also presents the theoretical risk of new lymphedema at the donor collection site. ${ }^{50}$ 

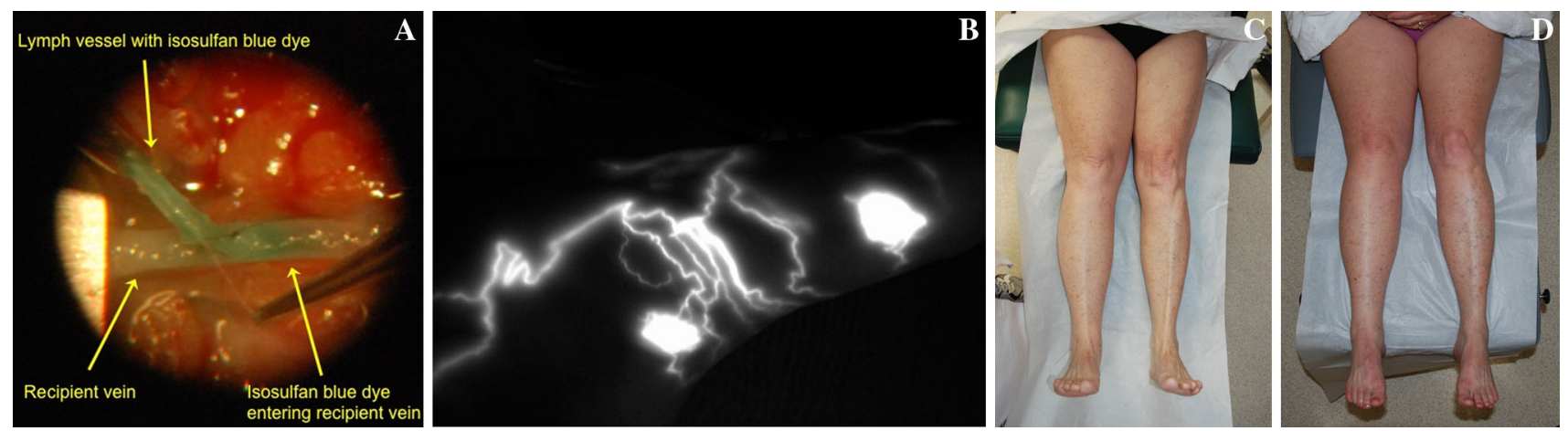

FIG. 4 LVA imaging. a Close-up view of anastomosis from lymphatic to vein end to side. b Intraoperative laser mapping of lymphatic pathways after intradermal indocyanine green dye injection. c, d Patient with right leg lymphedema after radical hysterectomy and radiotherapy treatment for uterine cancer treated with LVA of right leg. Before surgery, she required 60 hours of manual lymphatic drainage (MLD) per month and 30-40 mm Hg level compression stockings. Fifty-five months after LVA, she maintains decreased, stable requirement of 2-3 hours of MLD per month and single $20-30 \mathrm{mmHg}$ compression stocking on right leg. When she does have swelling, compression therapy to reduce this is much more effective and brings swelling down rapidly. c Before surgery. d At 55 months after surgery


FIG. 5 SAPL imaging. Patient with 46-year history of lymphedema of left leg previously treated ineffectively with open debulking (Sistrunk procedure) from thigh down to foot. Note long medial scar.

\section{SUCTION-ASSISTED PROTEIN LIPECTOMY (SAPL)}

SAPL addresses the excess solid volume remaining in a lymphedema-affected arm or leg after the fluid component has been maximally reduced with conventional, nonsurgical CDT and the patient has shown compliance with compression garment therapy afterward. The technique has been shown to reduce large amounts of volume excess effectively and consistently, with 1-year average reported reductions in volume excess in legs of $86 \%$ and more than $101 \%$ in arms (Fig. 5). ${ }^{11}$ Further reductions have been observed in subsequent years in prospective studies of 145 patients followed over an 8- to 15 -year period. ${ }^{51,52}$ More significantly, the incidence of dangerous cellulitis is reduced by $75 \%$ or more after the SAPL procedure. ${ }^{11,53}$ During the operation, excess proteinaceous fatty tissue from the affected limb is aspirated using power-assisted liposuction cannulas. The procedure is performed under
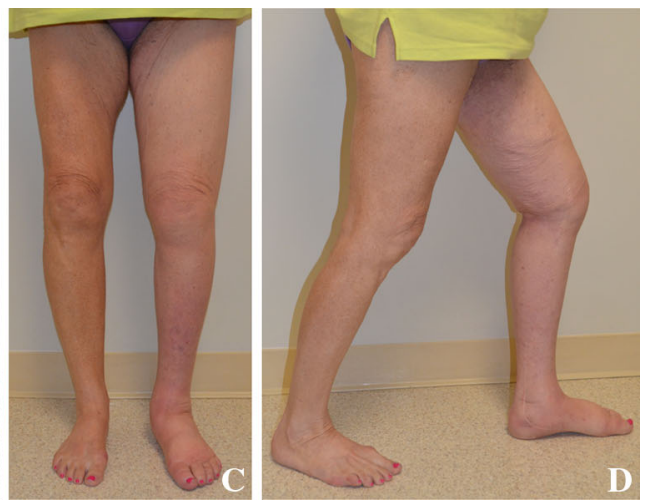

Patient was treated effectively with SAPL with volume reduction of $4,407 \mathrm{ml}$, representing $90 \%$ reduction in volume excess. a, b Before surgery. c, d At 21 months after surgery

general anesthesia in the operating room with a surgical tourniquet.

A successful SAPL outcome cannot be achieved without the integral involvement of a trained lymphedema therapist who is well versed in the procedure and its pre- and postoperative care. Custom-fit flat-knit compression garments are measured by the therapist and must be placed immediately after surgery in the operating room. Otherwise, if lymphedema bandaging is performed by the therapist in the operating room after surgery, then the custom compression garments can be placed by the therapist 1-2 days after the procedure. After surgery, patients remain in the hospital for several days until they can ambulate and remove and replace their compression garments independently.

While effectively removing excess volume, SAPL does not address the pathophysiology causing the lymphedema. Therefore, patients must continue postoperative compression to prevent reaccumulation of excess fluid. Additional 
postoperative therapy and manual lymphatic drainage can reduce swelling more rapidly, and new, custom-fit flat-knit garments must be remeasured and placed by the lymphedema therapist as the volume decreases in the months after surgery.

When performed correctly, the safety of SAPL has been established and has been found not to further damage the already impaired lymphatic flow in the affected patients studied. ${ }^{54}$ The technique of SAPL is a significant departure from that of conventional cosmetic liposuction and should not be attempted by surgeons not trained in the procedure. Damage to nerves and vessels, worsening of lymphatic flow, increased swelling and excess volume, and disruption of lymphatics by overaggressive or incorrect suctioning are risks if performed by an inexperienced surgeon. The postoperative compression garment protocol and lymphedema therapist treatment are also completely different than in cosmetic liposuction and are integral to the procedure's success.

We have combined the use of VLNT, LVA, and SAPL together with appropriate lymphedema therapy into an integrated treatment system. To our knowledge, this is the first comprehensive system to integrate traditional therapy and contemporary surgical techniques in order to address specifically the fluid and solid components of lymphedema. ${ }^{11}$ We find that patients whose disease is in the fluid phase are best treated with a physiologic procedure that promotes drainage of fluid from the extremity, such as VLNT or LVA. These patients are usually early in the disease process or may show some improvement with compression garment therapy. Lymphaticolymphatic bypass would apply to this phase but has not been used by our group. Patients in whom lymphedema has progressed to the solid phase, characterized by the deposition of excess lymphedema fat and proteins, are better treated with SAPL to remove this excess solid material.

Proper diagnosis and patient selection for the appropriate therapy and/or surgical procedure are central to the system's success. We think that selective application of the appropriate technique to treat fluid or solid phase lymphedema greatly improves overall patient outcomes. It is important to perform physiologic procedures such as VLNT or LVA while the patients are still in the fluid phase of their condition, before the depositions of excess solids occurs. A delay in treatment may allow solids to accumulate and may require patients to undergo SAPL treatment instead.

It should also be noted that procedures that address the fluid component of lymphedema, such as VLNT or LVA, are less likely to achieve the large reductions of excess volumes observed after SAPL. ${ }^{48,55,56}$ Rather, the procedures will significantly decrease the postoperative need for compression garments and lymphedema therapy.
Conversely, SAPL results in large volume reductions because it can remove the large amounts of solid fat and proteinaceous material, but it does not address ongoing lymphatic stasis and obstruction. ${ }^{11}$ Therefore, SAPL and VLNT procedures have been combined in a staged approach to manage chronic solid-phase lymphedema. First SAPL is performed to remove the proteinaceous solids and reduce volume excess. After postoperative swelling stabilizes, VLNT is used to improve lymphatic drainage and address subsequent fluid reaccumulation. This combined approach has resulted in volume reductions of over $83 \%$ with compression garment use required only in the evenings and at night. ${ }^{57}$

In conclusion, surgical techniques to treat lymphedema have evolved tremendously from the disfiguring procedures of the past. Together with integrated lymphedema therapy, proper diagnosis, and the appropriate selection of procedure, safe surgical techniques can be used to treat lymphedema effectively in many patients. The techniques described have been demonstrated to be effective in multiple studies and are no longer considered experimental. Standard precautions, such as vigilance with cuts and scratches in the affected limb and bandaging or compression with flying or at-risk activities, should be continued in all lymphedema patients, regardless of whether they have undergone surgical treatment. We are optimistic that further research and investigation will continue to improve our understanding and ability to treat this complex disease process.

ACKNOWLEDGMENT The authors declare no conflict of interest.

\section{REFERENCES}

1. Cormier JN, Askew RL, Mungovan KS, et al. Lymphedema beyond breast cancer: a systematic review and meta-analysis of cancer-related secondary lymphedema. Cancer. 2010;116:513849.

2. Schook CC, Mulliken JB, Fishman SJ, Grant FD, Zurakowski D, Greene AK. Primary lymphedema: clinical features and management in 138 pediatric patients. Plast Reconstr Surg. 2011;127:2419-31.

3. Kim JH, Choi JH, Ki EY, et al. Incidence and risk factors of lower-extremity lymphedema after radical surgery with or without adjuvant radiotherapy in patients with FIGO stage I to stage IIA cervical cancer. Int J Gynecol Cancer. 2012;22:686-91.

4. Petrek JA, Senie RT, Peters M, Rosen PP. Lymphedema in a cohort of breast carcinoma survivors 20 years after diagnosis. Cancer. 2001;92:1368-77.

5. Wilke LG, McCall LM, Posther KE, et al. Surgical complications associated with sentinel lymph node biopsy: results from a prospective international cooperative group trial. Ann Surg Oncol. 2006; 13:491e500.

6. Chang SB, Askew RL, Xing Y, et al. Prospective assessment of postoperative complications and associated costs following inguinal lymph node dissection (ILND) in melanoma patients. Ann Surg Oncol. 2010;17:2764-72. 
7. Hunt KK, Askew R, Cormier JN. Measuring lymphedema in patients with breast cancer: go with the flow? Breast Cancer Res Treat. 2009;117:559-60.

8. Disipio T, Rye S, Newman B, Hayes S. Incidence of unilateral arm lymphoedema after breast cancer: a systematic review and meta-analysis. Lancet Oncol. 2013;14:500-15.

9. Ryan TJ. Lymphatics and adipose tissue. Clin Dermatol. 1995;13:493.

10. Warren AG, Brorson H, Borud LJ, Slavin SA. Lymphedema: a comprehensive review. Ann Plast Surg. 2007;59:464-72.

11. Granzow JW, Soderberg JM, Kaji AH, Dauphine C. An effective system of surgical treatment of lymphedema. Ann Surg Oncol. doi:10.1245/s10434-014-3515-y.

12. Brorson H. From lymph to fat: liposuction as a treatment for complete reduction of lymphedema. Int $J$ Extrem Wounds. 2012;11:10-9.

13. Brorson H, Ohlin K, Olsson G, Karlsson MK. Breast cancerrelated chronic arm lymphedema is associated with excess adipose and muscle tissue. Lymphat Res Biol. 2009;7:3-10.

14. Lerner R. Complete decongestive physiotherapy and the Lerner Lymphedema Services Academy of Lymphatic Studies (the Lerner School) (review). Cancer. 1998;83(12 Suppl Am):2861-3.

15. International Society of Lymphology. The diagnosis and treatment of peripheral lymphedema. Consensus document. http://www.u. arizona.edu/*witte/2009consensus.pdf. Accessed 31 Aug 2013.

16. National Lymphedema Network. The diagnosis and treatment of lymphedema. Position paper. http://www.lymphnet.org/pdfDocs/ nlntreatment.pdf. Accessed 31 Aug 2013.

17. Ridner SH, Poage-Hooper E, Kanar C, Doersam JK, Bond SM, Dietrich MS. A pilot randomized trial evaluating low-level laser therapy as an alternative treatment to manual lymphatic drainage for breast cancer-related lymphedema. Oncol Nurs Forum. 2013;40:383-93.

18. Dayes IS, Whelan TJ, Julian JA, et al. Randomized trial of decongestive lymphatic therapy for the treatment of lymphedema in women with breast cancer. J Clin Oncol. 2013;31:3758-63.

19. Shih YC, Xu Y, Cormier JN, et al. Incidence, treatment costs, and complications of lymphedema after breast cancer among women of working age: a 2-year follow-up study. J Clin Oncol. 2009;27:2007-14.

20. Partsch H, Stout N, Forner-Cordero I, et al. Clinical trials needed to evaluate compression therapy in breast cancer related lymphedema (BCRL). Proposals from an expert group (review). Int Angiol. 2010;29:442-53.

21. Johansson K, Piller N. Weight-bearing exercise and its impact on arm lymphoedema. J Lymphoedema. 2007;2:15-22.

22. Brorson $\mathrm{H}$, Ohlin $\mathrm{K}$, Olsson $\mathrm{G}$, Långström $\mathrm{G}$, Wiklund $\mathrm{I}$, Svensson H. Quality of life following liposuction and conservative treatment of arm lymphedema. Lymphology. 2006;39:8-25.

23. Ruocco V, Schwartz RA, Ruocco E. Lymphedema: an immunologically vulnerable site for development of neoplasms. $J \mathrm{Am}$ Acad Dermatol. 2002;47:124.

24. Sharma A, Schwartz RA. Stewart-Treves syndrome: pathogenesis and management. $J$ Am Acad Dermatol. 2012;67:1342-8.

25. Charles H. Elephantiasis of the leg. In: Latham A, English TC, editors. A system of treatment. Vol. 3. London: Churchill; 1912.

26. Sistrunk WE. Contribution to plastic surgery: removal of scars by stages; an open operation for extensive laceration of the anal sphincter; the Kondoleon operation for elephantiasis. Ann Surg. 1927;85:185-93.

27. Thompson N. The surgical treatment of chronic lymphedema of the extremities. Surg Clin North Am. 1967;47:445-503.

28. Thompson N. Buried dermal flap operation for chronic lymphedema of the extremities: ten-year survey of results in 79 cases. Plast Reconstr Surg. 1970;45:541-8.
29. Becker C, Hidden G, Godart $\mathrm{S}$, et al. Free lymphatic transplant. Eur J Lymphol Rel Prob. 1991;6:25-77.

30. Becker C, Assouad J, Riquet M, Hidden G. Postmastectomy lymphedema: long-term results following microsurgical lymph node transplantation. Ann Surg. 2006;243:313-5.

31. Becker C, Vasile JV, Levine JL, Batista BN, Studinger RM, Chen CM, Riquet M. Microlymphatic surgery for the treatment of iatrogenic lymphedema. Clin Plast Surg. 2012;39:385-98.

32. Saaristo AM, Niemi TS, Viitanen TP, Tervala TV, Hartiala P, Suominen EA. Microvascular breast reconstruction and lymph node transfer for postmastectomy lymphedema patients. Ann Surg. 2012;255:468-73.

33. Belcaro G, Errichi BM, Cesarone MR, et al. Lymphatic tissue transplant in lymphedema-a minimally invasive, outpatient, surgical method: a 10-year follow-up pilot study. Angiology. 2008;59:77-83.

34. Lin $\mathrm{CH}$, Ali R, Chen SC, Wallace C, Chang YC, Chen HC, Cheng $\mathrm{MH}$. Vascularized groin lymph node transfer using the wrist as a recipient site for management of postmastectomy upper extremity lymphedema. Plast Reconstr Surg. 2009;123:1265-75.

35. Cheng MH, Huang JJ, Nguyen DH, Saint-Cyr M, Zenn MR, Tan BK, Lee CL. A novel approach to the treatment of lower extremity lymphedema by transferring a vascularized submental lymph node flap to the ankle. Gynecol Oncol. 2012;126:93-8.

36. Gharb BB, Rampazzo A, Spanio di Spilimbergo S, Xu ES, Chung $\mathrm{KP}$, Chen HC. Vascularized lymph node transfer based on the hilar perforators improves the outcome in upper limb lymphedema. Ann Plast Surg. 2011;67:589-93.

37. Chang DW, Kim S. Breast reconstruction and lymphedema. Plast Reconstr Surg. 2010;125:19-23.

38. Slavin SA, Upton J, Kaplan WD, et al. An investigation of lymphatic function following free-tissue transfer. Plast Reconstr Surg. 1997;99:730.

39. Tobbia D, Semple J, Baker A, Dumont D, Johnston M. Experimental assessment of autologous lymph node transplantation as treatment of postsurgical lymphedema. Plast Reconstr Surg. 2009;124:777-86.

40. Viitanen TP, Mäki MT, Seppänen MP, Suominen EA, Saaristo AM. Donor site lymphatic function after microvascular lymph node transfer. Plast Reconstr Surg. 2012;130:1246-53.

41. Vignes S, Blanchard M, Yannoutsos A, Arrault M. Complications of autologous lymph-node transplantation for limb lymphoedema. Eur J Vasc Endovasc Surg. 2013;45:516-20.

42. Obrien BM, Sykes PJ, Threlfall GN, Browning FS. Microlymphaticovenous anastomoses for obstructive lymphedema. Plast Reconstr Surg. 1977;60:197-211.

43. Mihara M, Uchida G, Hara H, et al. Lymphaticovenous anastomosis for facial lymphoedema after multiple courses of therapy for head-and-neck cancer. J Plast Reconstr Aesthet Surg. 2011;64:1221-5.

44. Campisi C, Eretta C, Pertile D, et al. Microsurgery for treatment of peripheral lymphedema: long-term outcome and future perspectives. Microsurgery. 2007;27:333-8.

45. Campisi C, Davini D, Bellini C, et al. Lymphatic microsurgery for the treatment of lymphedema. Microsurgery. 2006;26:65-9.

46. Koshima I, Inagawa K, Urushibara K, Moriguchi T. Supermicrosurgical lymphaticovenular anastomosis for the treatment of lymphedema in the upper extremities. J Reconstr Microsurg. 2000; $16: 437-42$.

47. Koshima I, Nanba Y, Tsutsui T, Takahashi Y, Itoh S. Long-term follow-up after lymphaticovenular anastomosis for lymphedema in the leg. J Reconstr Microsurg. 2003;19:209-15.

48. Chang DW. Lymphaticovenular bypass for lymphedema management in breast cancer patients: a prospective study. Plast Reconstr Surg. 2010;126:752-8. 
49. Baumeister RG, Siuda S, Bohmert H, Moser E. A microsurgical method for reconstruction of interrupted lymphatic pathways: autologous lymph-vessel transplantation for treatment of lymphedemas. Scand J Plast Reconstr Surg. 1986;20:141-6.

50. Suami H, Chang DW. Overview of surgical treatments for breast cancer-related lymphedema (review). Plast Reconstr Surg. 2010;126:1853-63.

51. Brorson H, Freccero C, Ohlin K, Svensson B. Liposuction of postmastectomy arm lymphedema completely removes excess volume: a 15 year study. Lymphology. 2010;43(Suppl):108-10.

52. Brorson H, Ohlin K, Olsson G, Svensson B. Liposuction normalized elephantiasis of the leg: a prospective study. Eur $J$ Lymphol. 2007;17:8.

53. Brorson H, Svensson H. Skin blood flow of the lymphedematous arm before and after liposuction. Lymphology. 1997:30:165-72.
54. Brorson H, Svensson H, Norrgren K, Thorsson O. Liposuction reduces arm lymphedema without significantly altering the already impaired lymph transport. Lymphology. 1998;31:156-72.

55. Damstra RJ, Voesten HGJ, van Schleven WD, van der Lei B. Lymphatic venous anastomosis (LVA) for treatment of secondary arm lymphedema. A prospective study of 11 LVA procedures in 10 patients with breast cancer related lymphedema and a critical review of the literature. Breast Cancer Res Treat. 2009;113:199_ 206.

56. National Lymphedema Network. Chen C. Autologous lymph node transfer: an update. http://www.lymphnet.org/newsletter/ newsletter.htm (2013). Accessed 29 Jan 2013.

57. Granzow JW, Soderberg JM, Dauphine C. A novel two-stage surgical approach to treat chronic lymphedema. Breast J. In press. 